\title{
Mammalian Elongin A complex mediates DNA-damage-induced ubiquitylation and degradation of Rpb1
}

\section{Takashi Yasukawa ${ }^{1}$, Takumi Kamura², Shigetaka Kitajima ${ }^{3}$, Ronald C Conaway ${ }^{4,5}$, Joan W Conaway ${ }^{4,5}$ and Teijiro Aso ${ }^{1, *}$}

${ }^{1}$ Department of Functional Genomics, Kochi Medical School, Kohasu, Oko-cho, Nankoku City, Kochi, Japan, ${ }^{2}$ Division of Biological Science, Graduate School of Science, Nagoya University, Furo-cho, Chikusa-ku, Nagoya City, Aichi, Japan, ${ }^{3}$ Department of Biochemical Genetics, Medical Research Institute, Tokyo Medical and Dental University, Yushima, Bunkyo-ku, Tokyo, Japan, ${ }^{4}$ Stowers Institute for Medical Research, Kansas City, MO, USA and ${ }^{5}$ Department of Biochemistry and Molecular Biology, Kansas University Medical Center, Kansas City, KS, USA

The Elongin complex stimulates the rate of transcription elongation by RNA polymerase II (pol II) by suppressing transient pausing of the pol II at many sites along the DNA. Elongin is composed of a transcriptionally active A subunit and two small regulatory $B$ and $C$ subunits, which can form an isolable Elongin $\mathrm{BC}$ subcomplex. Here, we have shown that both the ubiquitylation and proteasomal degradation of the largest subunit of pol II (Rpb1) following UV-irradiation are significantly suppressed in Elongin A-deficient cells; however, in both cases suppression is rescued by transfection of wild-type Elongin A. Moreover, we have demonstrated that the Elongin A-Elongin BC complex is capable of assembling with the Cul5/Rbx 2 module, and that this hetero-pentamer complex efficiently ubiquitylates Rpb1 in vitro. Mechanistic studies indicate that colocalization of Elongin A and Cul5 in cells and the interaction of Elongin A with the Ser5-phosphorylated form of Rpb1 are strongly enhanced following UV-irradiation. Taken together, our results suggest that mammalian Elongin $A$ is directly involved in ubiquitylation and degradation of Rpb1 following DNA damage.

The EMBO Journal (2008) 27, 3256-3266. doi:10.1038/

emboj.2008.249; Published online 27 November 2008

Subject Categories: chromatin \& transcription

Keywords: Cullin; E3 ubiquitin ligase; Elongin; RNA

polymerase II; transcription elongation

\section{Introduction}

Eukaryotic mRNA synthesis by RNA polymerase II (pol II) is regulated by the concerted action of a set of transcription factors that control the activity of pol II during the initiation and elongation stages of transcription. At least six general

\footnotetext{
*Corresponding author. Department of Functional Genomics, Kochi Medical School, Kohasu, Oko-cho, Nankoku City, Kochi 783-8505, Japan. Tel.: +81 88880 2279; Fax: + 8188880 2281;

E-mail: asot@kochi-u.ac.jp
}

Received: 7 August 2008; accepted: 5 November 2008; published online: 27 November 2008 transcription factors have been identified in eukaryotic cells and found to promote the selective binding of pol II to promoters and to support a basal level of transcription (Roeder, 1996). In addition, a diverse collection of elongation factors that promote efficient elongation of transcripts by pol II in vitro have also been identified (Conaway et al, 2000; Shilatifard et al, 2003; Sims et al, 2004). These factors fall into two broad functional classes based on their ability either to reactivate arrested pol II or to suppress the transient pausing of pol II. The first class is composed of members of the SII family (Wind and Reines, 2000; Shilatifard et al, 2003; Sims et al, 2004). The second class comprises a collection of elongation factors, including TFIIF (Price et al, 1989), Elongin (Bradsher et al, 1993; Aso et al, 1995), ELL (Shilatifard et al, 1996) and CSB (Selby and Sancar, 1997), which increase the overall rate of mRNA chain elongation by decreasing the frequency and/or duration of transient pausing by pol II at sites along the DNA template.

Elongin was identified as a heterotrimer composed of A, B, and $C$ subunits of $\sim 770,118$, and 112 amino acids, respectively (Bradsher et al, 1993; Garrett et al, 1994, 1995; Aso et al, 1995). Elongin A is the transcriptionally active subunit, whereas Elongins $\mathrm{B}$ and $\mathrm{C}$ are positive regulatory subunits that can form an isolable Elongin BC subcomplex (Aso et al, 1995, 1996; Duan et al, 1995). Two additional Elongin A family members, Elongin A2 and Elongin A3, have been identified in mammalian cells (Aso et al, 2000; Yamazaki et al, 2002). All three Elongin A proteins function similarly to stimulate the overall rate of elongation by pol II in vitro and have been shown to bind to the Elongin $\mathrm{BC}$ complex through a 10-amino acid degenerate sequence motif referred to as the BC-box with consensus [(T,S,P)LXXX(C,A,S)XXX(V,I,L)]. Recently, Elongin A was found to belong to a larger family of Elongin BC-box proteins that can all be linked through Elongins $\mathrm{B}$ and $\mathrm{C}$ to a heterodimeric module composed of Cullin family proteins Cul2 or Cul5 and the RING finger proteins Rbx1 or Rbx2 to form multisubunit complexes that can function as E3 ubiquitin ligases (Kamura et al, 2001). The best characterized of these Elongin BC-based ubiquitin ligases is the von Hippel-Lindau (VHL) tumour suppressor complex, where the VHL protein serves as a substrate recognition subunit that recruits target proteins for ubiquitylation and the Cullin/Rbx module functions to activate ubiquitylation of target proteins by an E2 ubiquitin-conjugating enzyme. Although it remained unknown whether Elongin A actually functions as a substrate recognition subunit of ubiquitin ligases and, if so, what its substrates might be, it has been speculated that one function of Elongin A may be to recruit a Cullin/Rbx module directly to transcription elongation complexes to target ubiquitylation of pol II or other components of the transcription apparatus (Shilatifard et al, 2003). Indeed, Prakash and co-workers have recently reported that yeast homologues of mammalian Elongin A 
and Elongin C (Ela1 and Elc1, respectively) appeared to be required for ubiquitylation and subsequent degradation of the largest subunit of pol II (Rpb1) in DNA-damaged yeast cells (Ribar et al, 2007).

In this study, we have investigated the role of Elongin A in ubiquitylation and degradation of Rpb1 in mammalian cells. Using recombinant proteins expressed in insect cells, we have shown that Elongin A is capable of assembling with the Cul5/ Rbx2 module through Elongins B and C, and that this heteropentamer complex efficiently ubiquitylates Rpb1 in vitro. Moreover, degradation of Rpb1 following UV-irradiation is significantly inhibited by the reduced expression of Elongin A and Cul5. Taken together, our results suggest that mammalian Elongin $\mathrm{A}$ is directly involved in ubiquitylation and degradation of Rpb1, both in vitro and in vivo.

\section{Results}

\section{Stability of hyperphosphorylated Rpb1 following DNA damage is increased in Elongin A-deficient cells}

It has been shown that DNA damage causes phosphorylation of a subpopulation of pol II, followed by ubiquitylation and subsequent degradation by the proteasome (Ratner et al, 1998; Luo et al, 2001; McKay et al, 2001). To examine whether Elongin $\mathrm{A}$ is involved in ubiquitin-mediated degradation of pol II, the protein levels of Rpb1 after DNA damage were compared in Elongin $\mathrm{A}^{+/+}$and Elongin $\mathrm{A}^{-/-} \mathrm{ES}$ cells. As shown in Figure 1A, the level of the hypophosphorylated form of Rpb1 (pol IIA) detected with 8WG16 decreased dramatically in Elongin $\mathrm{A}^{+/+}$ES cells following treatment with UV or cisplatin. In contrast, the pol IIA levels were substantially less reduced in Elongin $\mathrm{A}^{-/-}$ES cells. To confirm that the observed diminution of pol IIA in Elongin $\mathrm{A}^{+/+}$ ES cells after DNA damage is due to phosphorylation of its Cterminal domain (CTD) and conversion into the hyperphosphorylated form (pol IIO), Elongin $\mathrm{A}^{+/+}$and Elongin $\mathrm{A}^{-/-}$ ES cells were UV-irradiated and allowed to recover for the indicated periods of time in the presence or absence of the CTD-kinase inhibitors $\mathrm{H} 7$ and DRB. As shown in Figure 1B, the UV-induced decline of pol IIA in Elongin $\mathrm{A}^{+/+}$ES cells was indeed prevented by either of these CTD-kinase inhibitors. An appropriate interpretation of these results therefore is that DNA-damage-induced ubiquitylation and subsequent degradation of pol IIO prevent its being recycled (through dephosphorylation) to pol IIA, so that the steady-state level of pol IIA diminishes in Elongin $\mathrm{A}^{+/+}$ES cells. In Elongin $\mathrm{A}^{-/-}$ ES cells, however, the ubiquitin-mediated degradation of Rpb1 is possibly impaired so that the steady-state level of pol IIA is less significantly altered compared with Elongin $\mathrm{A}^{+/+}$ES cells.

To further evaluate the effect of Elongin A on the degradation of Rpb1, the rate of decay of Rpb1 in the presence of cycloheximide was measured in Elongin $\mathrm{A}^{+/+}$, Elongin $\mathrm{A}^{-/-}$ ES cells, and Elongin $A^{-/-}$ES cells transfected with wild-type Elongin A (Elongin $\mathrm{A}^{-/-}+$Elongin A ES cells). As shown in western blots with N20, which recognizes both pol IIA and pol IIO, the decrease of the level of pol IIO following UVirradiation was significantly delayed in Elongin $\mathrm{A}^{-/-}$ES cells compared with Elongin $\mathrm{A}^{+/+}$ES cells; however, the delay observed in Elongin $\mathrm{A}^{-/-}$ES cells was overcome by the introduction of wild-type Elongin A (Figure 1C). In addition, the diminution of pol IIO in Elongin A-expressing cells is
A

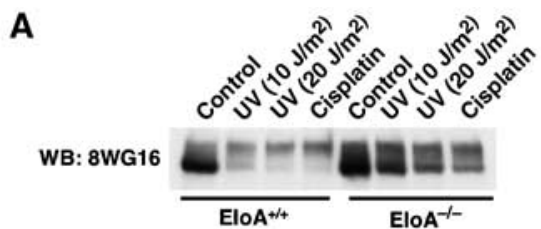

C

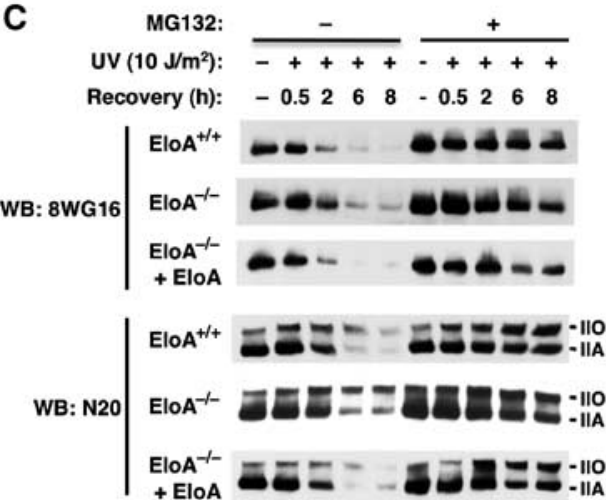

B

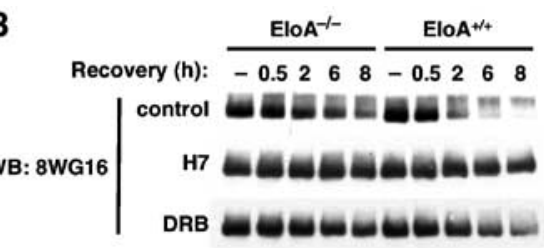

D

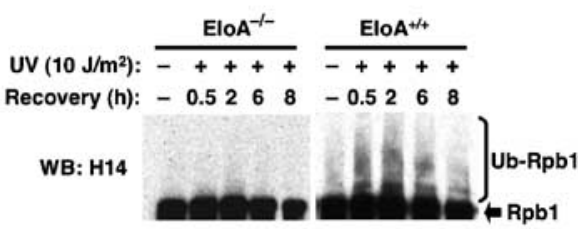

Figure 1 Stability of Rpb1 following DNA damage is increased in Elongin $\mathrm{A}^{-/-}$ES cells. (A) Elongin $\mathrm{A}^{+/+}$and Elongin $\mathrm{A}^{-/-}$ES cells were treated with UV-irradiation (10 or $\left.20 \mathrm{~J} / \mathrm{m}^{2}\right)$ or cisplatin $(20 \mu \mathrm{g} / \mathrm{ml})$ and recovered for $8 \mathrm{~h}$ in the presence of the protein synthesis inhibitor cycloheximide. Total cell lysates were prepared, separated by 6\% SDS-PAGE, and immunoblotted with 8 WG16 antibody. (B) Elongin A $+/+$ and Elongin $\mathrm{A}^{-1-}$ ES cells were treated with UV-irradiation $\left(10 \mathrm{~J} / \mathrm{m}^{2}\right)$ and recovered for the indicated period of time in the presence of cycloheximide with or without the CTD-kinase inhibitors H7 and DRB. Total cell lysates were prepared, separated by 6\% SDS-PAGE, and immunoblotted with 8 WG16 antibody. (C) Elongin $\mathrm{A}^{+/+}$, Elongin $\mathrm{A}^{-/-}$ES cells, and Elongin $\mathrm{A}^{-/-}$ES cells transfected with Elongin A were treated with UV-irradiation $\left(10 \mathrm{~J} / \mathrm{m}^{2}\right)$ and recovered for the indicated period of time in the presence of cycloheximide with or without the proteasomal inhibitor MG132. Total cell lysates were prepared, separated by 6\% SDS-PAGE, and immunoblotted with 8 WG16 or N20 antibody. (D) Elongin $\mathrm{A}^{+/+}$and Elongin $\mathrm{A}^{-/-}$ES cells were treated with UV-irradiation $\left(10 \mathrm{~J} / \mathrm{m}^{2}\right)$ and recovered for the indicated period of time in the presence of MG132. Total cell lysates were prepared, separated by 6\% SDS-PAGE, and immunoblotted with H14 antibody. 
prevented by the proteasomal inhibitor MG132, indicating that the loss of pol IIO results from proteasomal degradation. Furthermore, UV-irradiation clearly stimulated the formation of a high molecular mass smear characteristic of ubiquitinconjugates in Elongin $\mathrm{A}^{+/+}$ES cells, but failed to induce its formation in Elongin $\mathrm{A}^{-1-}$ ES cells (Figure 1D). Taken together, our results suggest that mammalian Elongin A functions in targeting pol IIO for degradation through the ubiquitin-mediated proteolysis pathway in response to DNA damage.

\section{The Elongin A-Elongin BC complex assembles with a Cul5/Rbx2 module to reconstitute a ubiquitin ligase of $R p b 1$}

VHL and other Elongin BC-box proteins can assemble with the Elongin $\mathrm{BC}$ complex and a heterodimeric module composed of a member of the Cullin protein family and RING finger protein Rbx1 or Rbx2 to form multiprotein ubiquitin ligase complexes (Kamura et al, 1999, 2000, 2001, 2004).
In mammalian cells the Cullin protein family includes at least five members, referred to as Cul1, Cul2, Cul3, Cul4, and Cul5 (Kipreos et al, 1996). Each of these Cullin proteins has been shown to assemble with either Rbx1 or Rbx2 to reconstitute a module that is capable of activating ubiquitylation by E2 ubiquitin-conjugating enzymes (Ohta et al, 1999; Kamura et al, 2001, 2004).

To confirm that the Elongin A-Elongin BC complex can assemble into similar complexes, Sf9 insect cells were infected with combinations of baculoviruses encoding $3 \times$ Flag-Elongin A, Elongins B and C, $3 \times$ myc-Rbx2, mycRbx1, and individual Cullin proteins containing N-terminal HA epitope tags. When immunoprecipitations were performed with anti-HA and anti-Flag antibodies, Elongin A, Elongins $\mathrm{B}$ and $\mathrm{C}$, and Rbx2 could be specifically coimmunoprecipitated with HA-Cul5, but not with HA-Cul1, HA-Cul2, HA-Cul3, or HA-Cul4 (Figure 2A). Rbx2 was reproducibly present in all the anti-Flag immunoprecipitates. It is most likely that Rbx2 is linked to Elongin A through
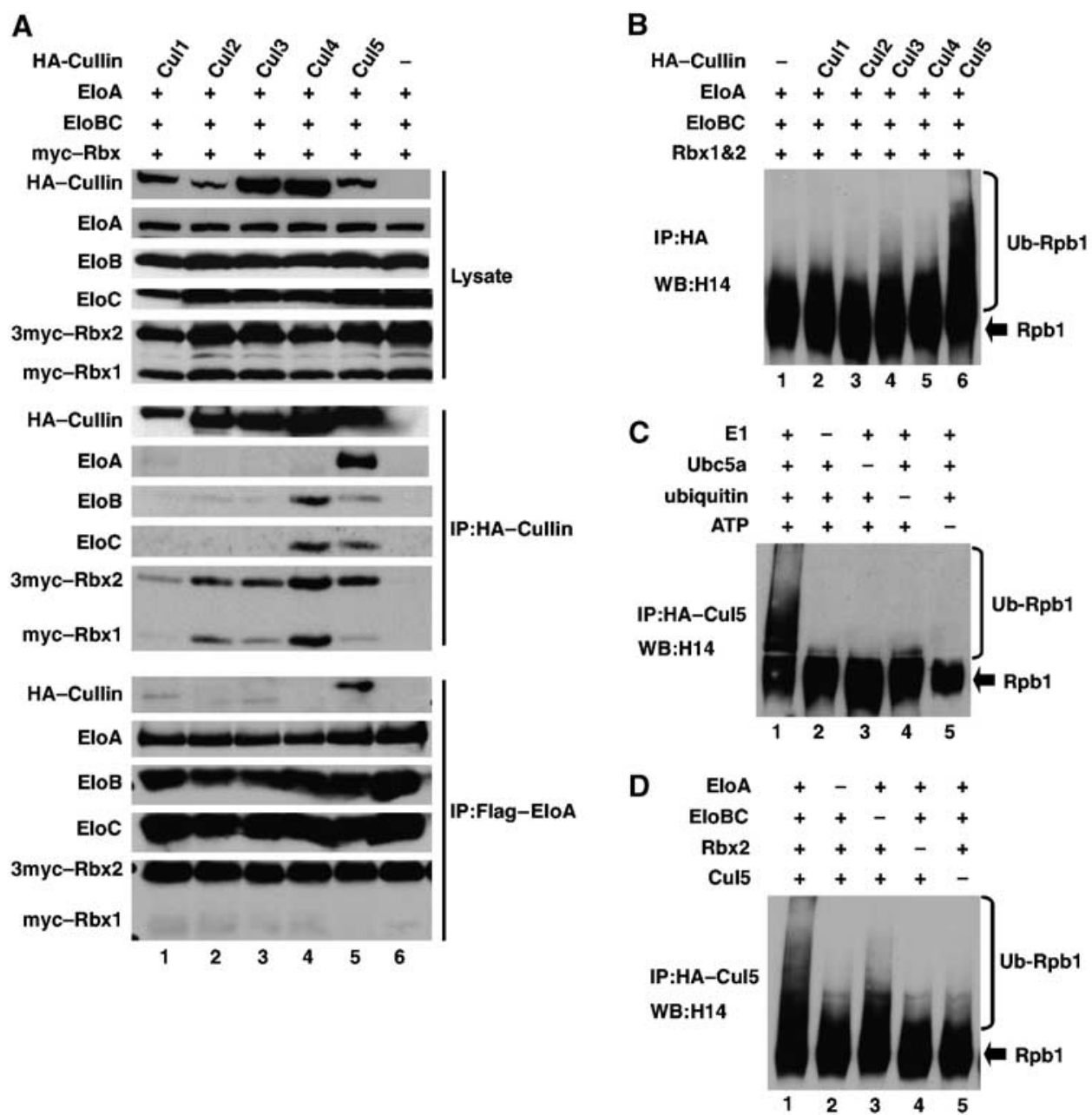

Figure 2 The Elongin A-Elongin BC complex assembles with a Cul5/Rbx2 module to reconstitute a ubiquitin ligase of Rpb1 in vitro. (A) Sf9 cells were coinfected with the baculoviruses indicated in the figure. Anti-HA and anti-Flag immunoprecipitations were performed as described under Materials and methods. Total cell lysates and anti-HA and anti-Flag immunoprecipitates were separated by SDS-PAGE and immunoblotted with the indicated antibodies. (B, D) Lysates from Sf9 cells infected with the indicated baculoviruses were immunoprecipitated with anti-HA antibody and were subjected to in vitro ubiquitylation assay as described under Materials and methods. Samples were analyzed on $6 \%$ SDS-PAGE and processed for western blotting with H14 antibody. (C) Lysates from Sf9 cells containing Elongin A, HA-Cul5, Rbxs 1 and 2, and Elongins B and C were immunoprecipitated with anti-HA antibody and were subjected to in vitro ubiquitylation assay as described under Materials and methods, with omission of E1 (lane 2), hUbc5a (lane 3), ubiquitin (lane 4), or ATP (lane 5) from reaction mixtures. Samples were analyzed on $6 \%$ SDS-PAGE and processed for western blotting with H14 antibody. 
endogenous insect cell Cul5, although we cannot rule out the possibility that $\mathrm{Rbx} 2$ is bound directly to Elongin A in these assays.

To determine whether the Elongin A-Elongin BC-Cul5Rbx2 complex possesses ubiquitin ligase activity for Rpb1, anti-HA immunoprecipitates from Sf9 cell lysates were assayed for their abilities to activate Rpb1 ubiquitylation in the presence of ATP, ubiquitin, E1, the E2 ubiquitin-conjugating enzyme hUbc5a, and purified pol II. As shown in Figure 2B, maximal activation of Rpb1 ubiquitylation was observed when reaction mixtures contained complexes purified from cells that were overexpressing Elongin A, Elongins B and C, Rbx proteins, and Cul5, but not other members of the Cullin family. Activation of Rpb1 ubiquitylation by the Elongin A complex was strongly dependent on ATP, ubiquitin, E1, and the E2 ubiquitin-conjugating enzyme hUbc5a (Figure 2C). To investigate the contributions of individual subunits of the Elongin A complex to Rpb1 ubiquitylation, Sf9 cells were coinfected with various combinations of baculoviruses encoding $3 \times$ Flag-Elongin A, Elongins B and C, $3 \times$ myc-Rbx 2 , and HA-Cul5. Anti-HA immunoprecipitates were then assayed for their abilities to activate Rpb1 ubiquitylation in the presence of ATP, ubiquitin, E1, hUbc5a, and purified pol II. As shown in Figure 2D, maximal activation of Rpb1 ubiquitylation was observed in the presence of Elongin Acontaining complexes purified from cells overexpressing all five subunits of the Elongin A complex. A low level of Rpb1 ubiquitylation was observed when reaction mixtures contained complexes purified from cells that were not overexpressing Elongins $\mathrm{B}$ and $\mathrm{C}$, most likely because of the presence of a substoichiometric amount of contaminating endogenous insect cell Elongins $\mathrm{B}$ and $\mathrm{C}$ in immunoprecipitated Elongin A complexes. These results, thus, demonstrate that the Elongin A-Elongin BC complex is capable of assembling with a Cul5/Rbx2 module to reconstitute a ubiquitin ligase that targets Rpb1.

\section{Localization of Elongin A regions important for the assembly and the Rpb1-ubiquitylation activity of the Elongin A ubiquitin ligase}

It has been reported recently that, in addition to the BC-box, mammalian Elongin A contains sequences similar to the

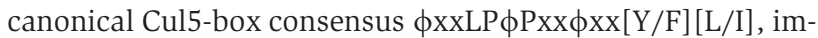
mediately downstream of the BC-box (Kamura et al, 2004; Mahrour et al, 2008) (Figure 3A). To investigate whether these BC-box and potential Cul5-box sequences of Elongin A are required for the assembly and the Rpb1 ubiquitylation activity of the Elongin A ubiquitin ligase, we compared the activities of wild-type Elongin A and three Elongin A mutants. An Elongin A double point mutant Elongin A[L550P;C554F] contains BC-box mutations that were shown previously to disrupt binding of the BC-box family members to the Elongin BC complex (Aso et al, 1996; Kamura et al, 1998). Internal deletion mutants Elongin $\mathrm{A}[\Delta(549-558)]$ and Elongin $\mathrm{A}[\Delta(568-588)]$ lack the BC-box and Cul5-box sequences, respectively.

Sf9 cells were coinfected with various combinations of baculoviruses encoding Elongins $\mathrm{B}$ and $\mathrm{C}, 3 \times$ myc-Rbx 2 , myc-Rbx1, HA-Cul5, and $3 \times$ Flag-tagged Elongin A, Elongin $\mathrm{A}[\mathrm{L} 550 \mathrm{P} ; \mathrm{C} 554 \mathrm{~F}]$, Elongin $\mathrm{A}[\Delta(549-558)]$, or Elongin $\mathrm{A}[\Delta(568-588)]$. Complexes were immunoprecipitated from cell lysates with anti-HA or anti-Flag antibody and analyzed (i) for the presence of individual subunits of the Elongin A complex by immunoblotting and (ii) for their abilities to activate Rpb1 ubiquitylation in the presence of ATP, ubiquitin, E1, the E2 ubiquitin-conjugating enzyme hUbc5a, and purified pol II. As shown in Figure 3B, Elongin A mutants, Elongin A[L550P;C554F] and Elongin A[ $\Delta$ (549558)] were severely, and Elongin $\mathrm{A}[\Delta(568-588)]$ was less severely, impaired in their abilities to bind to Elongins $\mathrm{B}$ and C. Consistent with the previous observation that entry of Cullins into the $\mathrm{BC}$-box protein complexes depends on the presence of Elongins B and C (Kamura et al, 2000, 2001), Cul5 was not as efficiently coimmunoprecipitated with Elongin $\mathrm{A}[\mathrm{L} 550 \mathrm{P} ; \mathrm{C} 554 \mathrm{~F}]$, Elongin $\mathrm{A}[\Delta(549-558)]$, or Elongin $\mathrm{A}[\Delta(568-588)]$ as wild-type Elongin A. Furthermore, antiHA immunoprecipitates purified from insect cells expressing Elongin A mutants, Elongin A[L550P;C554F], Elongin $\mathrm{A}[\Delta(549-558)]$, or Elongin $\mathrm{A}[\Delta(568-588)]$ failed to activate Rpb1 ubiquitylation above the low background level observed in the absence of Elongin A (Figure 3C).

In addition, we examined the requirement of the N-terminal SII similarity region and the elongation activation domain of Elongin A for activating Rpb1 ubiquitylation. As shown in Figure 3D, anti-HA immunoprecipitate purified from insect cells expressing Elongin A[121-773], which lacks the region similar to SII, exhibited a level of activity comparable with that of full-length Elongin A, suggesting that the $\mathrm{N}$ terminus of Elongin $\mathrm{A}$ is dispensable for activating Rpb1 ubiquitylation. The relative Rpb1 ubiquitylation activities of wild-type Elongin A and a series of N-terminal, Cterminal, and internal deletion mutants of Elongin A were then compared (Figure 3E). Anti-HA immunoprecipitates purified from insect cells expressing Elongin A deletion mutants lacking sequences between residues 521 and 680, which have been shown to be most critical for inducible activation of Elongin A transcriptional activity by Elongin BC (Aso et al, 1996), failed to activate Rpb1 ubiquitylation above the background level observed in the absence of Elongin A (Figure $3 \mathrm{~F}$ ). These results, therefore, demonstrate (i) that both the BC-box and Cul5-box sequences of Elongin A are essential for the proper assembly and Rpb1 ubiquitylation activity of the Elongin A ubiquitin ligase, and (ii) that the Elongin A region required for Rpb1 ubiquitylation is almost identical to the elongation activation domain of Elongin A.

\section{Elongin A colocalizes with Cul5 in cell nuclei after UV-irradiation}

We have previously shown that Elongin A is predominantly localized to the cell nucleus (Yasukawa et al, 2007). Although the distribution of Cul5 has been controversial, recent reports suggest that it migrates between the nucleus and cytoplasm depending on the cell cycle (Querido et al, 2001; Ceremuga et al, 2003; Burnatowska-Hledin et al, 2004). It is therefore important to determine whether Elongin A and Cul5 colocalize in cells after UV-irradiation. HeLa cells were UV-irradiated and fixed after the indicated period of time, and then localization of Elongin A, Cul5, and also Cul2 as a control was analyzed by laser confocal microscopy. Consistent with the previous results, Elongin A predominantly localized to the nucleus. Cul5 also primarily localized to the nucleus, as did Cul2. Before UV-irradiation, neither Cul5 nor Cul2 showed significant colocalization with Elongin A. However, 30-40 min after UV-irradiation, Cul5 (Figure 4A), but not 
A

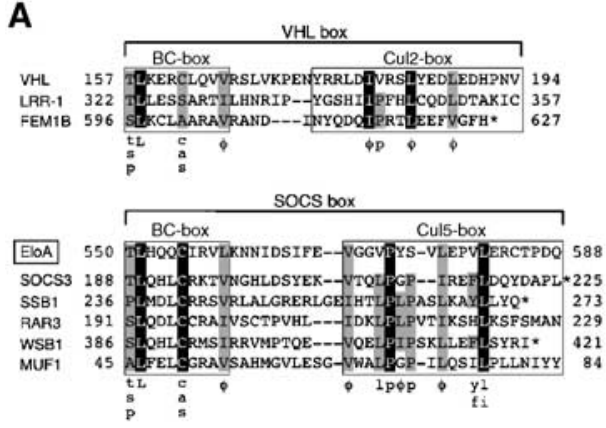

B

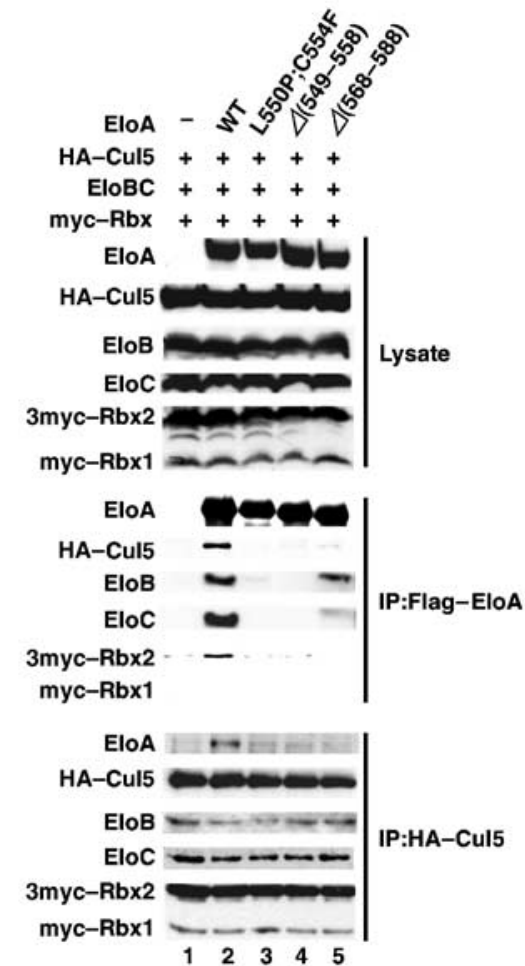

C

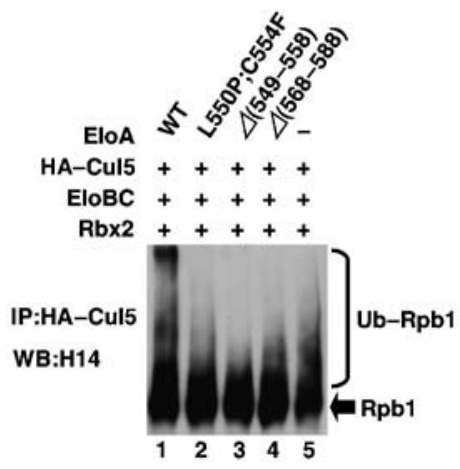

D

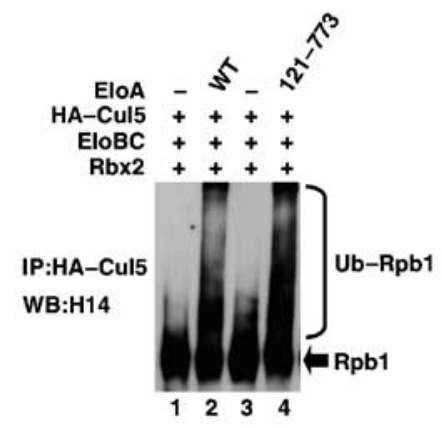

E

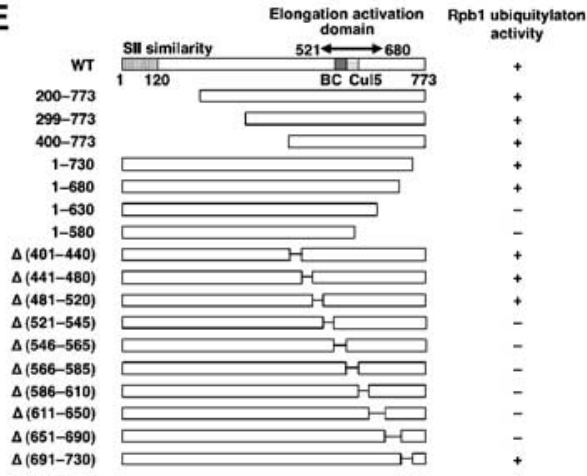

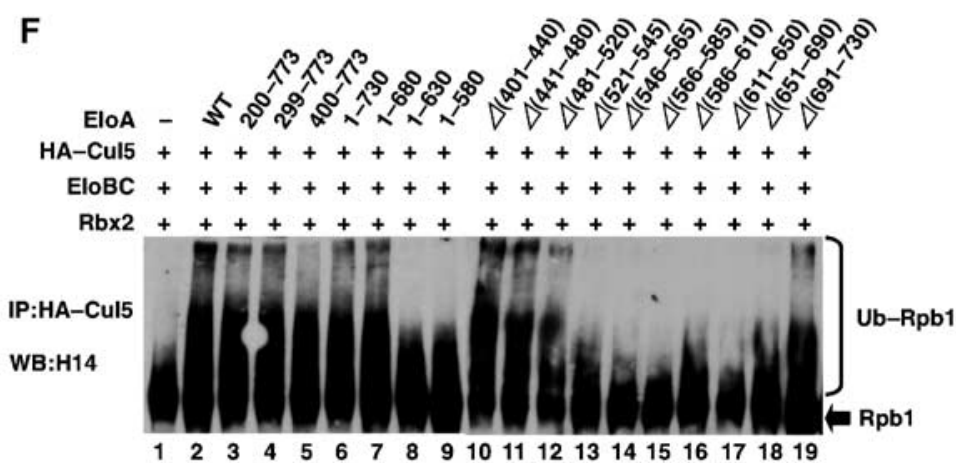

Figure 3 Localization of Elongin A regions required for the assembly and the Rpb1 ubiquitylation activity of the Elongin A ubiquitin ligase complex. (A) Alignment of amino acid sequences of VHL-box and SOCS-box proteins. The BC-box, Cul2-box, and Cul5-box are indicated (boxed). Identical (black) and similar (grey) amino acids are shaded. Asterisks indicate C termini. Sequences are of the human proteins. Sequences of the SOCS-box of Elongin A are perfectly conserved between human and rat, and correspond to amino acids 549-587 in rat Elongin A. The canonical BC-box and Cul5-box sequences and conserved Cul2-box residues are indicated below each alignment. (B) Sf9 cells were coinfected with the baculoviruses indicated in the figure. Anti-Flag and Anti-HA immunoprecipitations were performed as described under Materials and methods. Total cell lysates and anti-Flag and anti-HA immunoprecipitates were separated by SDS-PAGE and immunoblotted with the indicated antibodies. (C, D, F) Lysates from Sf9 cells infected with the indicated baculoviruses were immunoprecipitated with anti-HA antibody and were assayed for their ability to activate Rpb1 ubiquitylation as described under Materials and methods. Samples were analyzed on $6 \%$ SDS-PAGE and processed for western blotting with H14 antibody. (E) N-terminal, C-terminal, and internal deletion mutants of Elongin A analyzed in this study. On the right, the results of the assay shown in (F) are shown. 
A

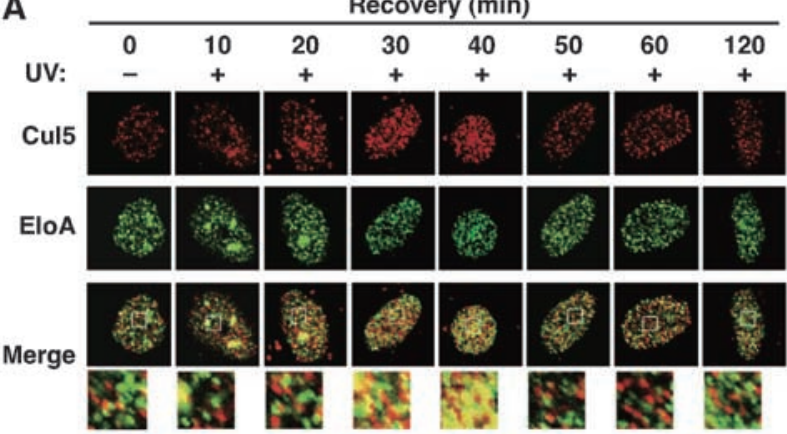

B

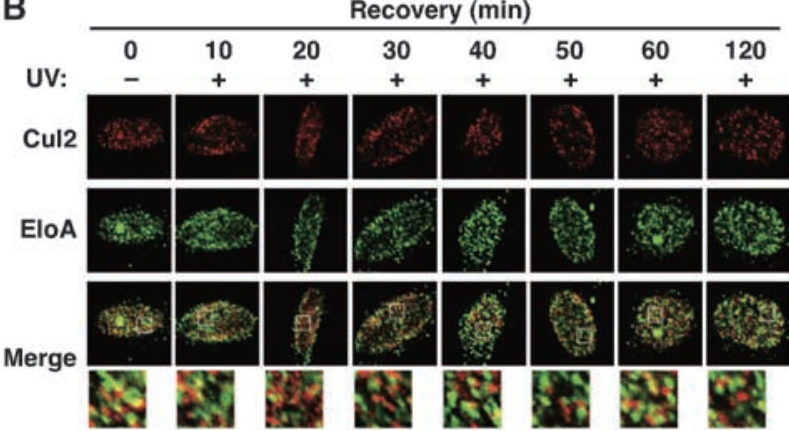

Figure 4 Intracellular colocalization of Elongin A and Cul5 after UV-irradiation. (A, B) HeLa cells treated with UV-irradiation $(10 \mathrm{~J} /$ $\mathrm{m}^{2}$ ) were incubated for the indicated period of time, then were fixed and analyzed by laser confocal microscopy. In panel A, Cul5 was detected using anti-Cul5 rabbit polyclonal antibody and Alexa 594 anti-rabbit IgG antibody (Top). Elongin A was detected using antiElongin A mouse monoclonal antibody and Alexa 488 anti-mouse IgG antibody (Middle). In panel B, Cul2 was detected using antiCul2 mouse monoclonal antibody and Alexa 488 anti-mouse IgG antibody (Top). Elongin A was detected using anti-Elongin A rabbit polyclonal antibody and Alexa 594 anti-rabbit IgG antibody (Middle). Merged images are displayed (Bottom). The box indicates the area that is enlarged. Images were pseudocoloured using Adobe Photoshop so that Elongin A is shown in green and Cul5 or Cul2 is shown in red. The areas of overlap appear as yellow.

Cul2 (Figure 4B), showed extensive colocalization with Elongin A in the nucleus. The transient nature of the colocalization of these two proteins suggests that the Elongin AElongin BC complex associates with a Cul5/Rbx2 module only temporarily in cells after UV-irradiation.

\section{Reduced expression of Elongin A and Cul5 inhibits the degradation of Ser5-phosphorylated Rpb1 following DNA damage}

To confirm the role of Elongin A and Cul5 in DNA-damageinduced degradation of pol IIO, we knocked down Elongin A or Cul5 in mouse embryonic fibroblasts (MEFs) or HeLa cells, respectively, by RNA interference (RNAi)-mediated gene silencing. Two independent sequences for each molecule were used as targets of RNAi. Cells infected with a retroviral vector encoding either Elongin A (EloA-1 or EloA-2) or Cul5 (Cul5-1 or Cul5-2) shRNAs specific for Elongin A or Cul5 mRNAs exhibited a significant decrease in the abundance of Elongin A or Cul5, respectively, compared with that apparent in cells infected with a control vector for EGFP shRNA (Figure 5A). Expression of EGFP shRNA did not affect Rpb1 degradation. The reduction in the level of pol IIO and Ser5phosphorylated Rpb1 detected with H14 following UV-irradiation, however, was significantly inhibited by expression of
Elongin A or Cul5 shRNAs (Figure 5B). The stability of Ser2phosphorylated Rpb1 detected with H5, however, was not significantly increased by these shRNAs. These results suggest that both Elongin A and Cul5, indeed, function in mediating preferential degradation of the Ser5-phosphorylated form of Rpb1 in response to DNA damage in vivo.

\section{Wild-type Elongin A, but not Elongin A[L550P;C554F], rescues delayed degradation of Rpb1 in Elongin A-deficient cells}

To confirm that the ubiquitylation mediated by Elongin A will result in a rapid turnover of pol IIO through proteasomal degradation in vivo, either wild-type Elongin A or Elongin A[L550P;C554F], which was unable to support pol II ubiquitylation in vitro, was transfected into Elongin $\mathrm{A}^{-/-}$ES cells, and the rate of decay of Ser5-phosphorylated Rpb1 following UV-irradiation in the presence of cycloheximide was measured in these cells. As shown in western blots with H14, the observed delay in the degradation of Rpb1 in Elongin $\mathrm{A}^{-/-} \mathrm{ES}$ cells was almost unchanged by the introduction of Elongin $\mathrm{A}[\mathrm{L} 550 \mathrm{P} ; \mathrm{C} 554 \mathrm{~F}]$, whereas the rate of decay of Rpb1 in Elongin $\mathrm{A}^{-1-}$ ES cells was significantly increased by the introduction of wild-type Elongin A (Figure 6). In addition, the degradation of Rpb1 induced by expression of wild-type Elongin A was prevented by the proteasomal inhibitor MG132. These results demonstrate that Ser5-phosphorylated Rpb1 undergoes proteasome-dependent degradation in an Elongin A-dependent manner in vivo, suggesting that Rpb1 is a target of Elongin A ubiquitin ligase for ubiquitylation and rapid degradation by the proteasome.

\section{$U V$-irradiation enhances the interaction of Elongin $A$ with the Ser5-phosphorylated form of Rpb1}

The effect of the Elongin A complex on Rpb1 ubiquitylation would most likely be achieved through a direct interaction between Elongin A and pol II. Such interactions might be constitutive, but also could be induced by DNA damage. To clarify these possibilities, Elongin $\mathrm{A}^{-/-}$ES cells transfected with Flag-tagged Elongin A were UV-irradiated, and cell extracts prepared at different times during recovery in the presence of MG132 were immunoprecipitated with anti-Flag antibody. The presence of Rpb1 in these immunoprecipitates was examined by immunoblotting (Figure 7). A low but clearly detectable level of the Ser5-phosphorylated form of Rpb1 coimmunoprecipitated with Elongin A in the absence of UV-irradiation (Figure 7, lane 1). However, a dramatic increase in the level of Ser5-phosphorylated Rpb1 associated with Elongin A was observed $30 \mathrm{~min}$ after UV-irradiation (Figure 7, lane 2). As cells recovered after UV-irradiation, detectable interaction between Elongin A and Ser5-phosphorylated Rpb1 also decreased (Figure 7, compare lanes 2, 3 , and 4), whereas neither unphosphorylated nor Ser2-phosphorylated forms of Rpb1 were detectable in those immunoprecipitates. These results, therefore, suggest that the primary target for Elongin A ubiquitin ligase may be the Ser5-phosphorylated form of Rpb1 and that they interact in a way that is strongly enhanced by UV-irradiation.

\section{Discussion}

In this report, we provide evidence (i) that both the ubiquitylation and proteasomal degradation of Rpb1 following UV- 


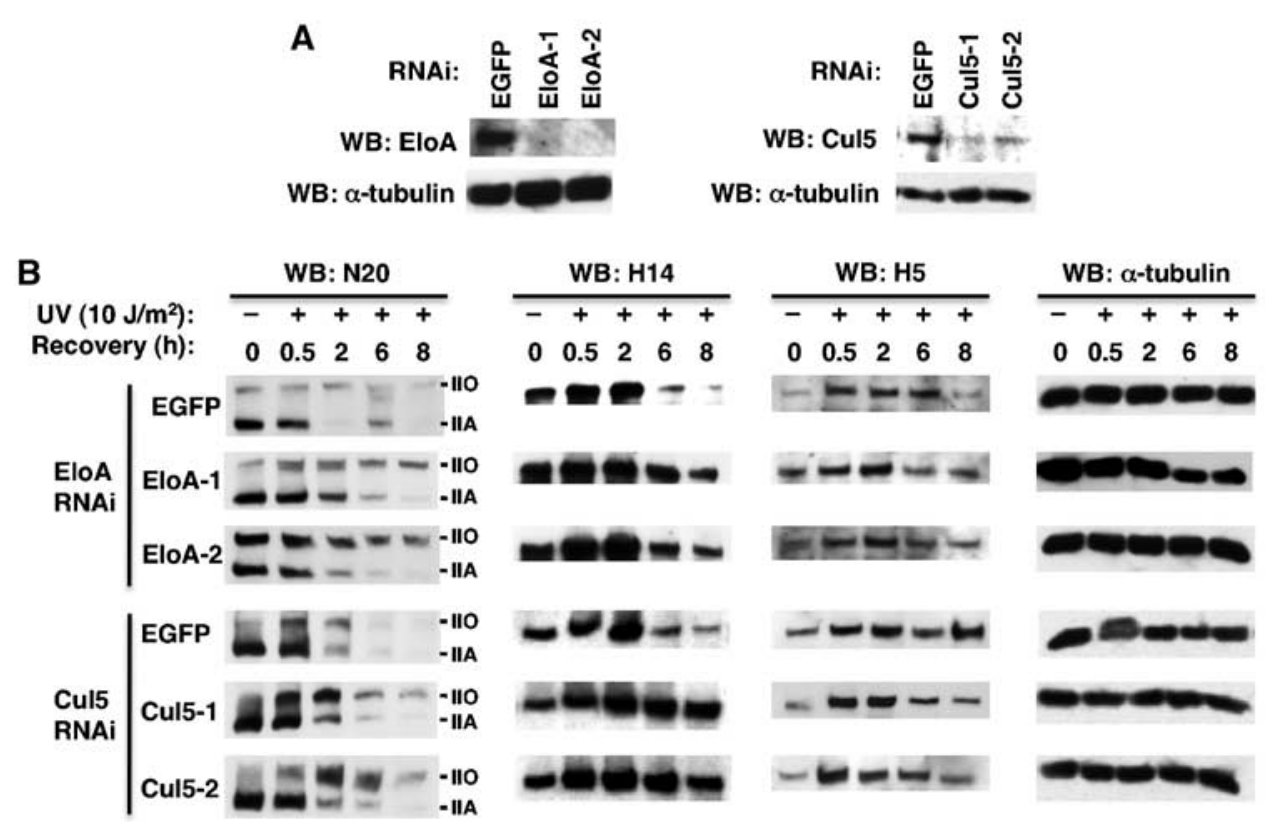

Figure 5 Effect of RNAi knockdown of Elongin A and Cul5 on the UV-induced degradation of Rpb1. (A, B) MEFs or HeLa cells were infected with a retroviral vector encoding either Elongin A (EloA-1 or EloA-2), Cul5 (Cul5-1 or Cul5-2), or EGFP (control) shRNAs. Lysates of the cells were subjected to western blot analysis with anti-Elongin A, anti-Cul5, N20, H14, H5, or anti- $\alpha$-tubulin antibody (control).

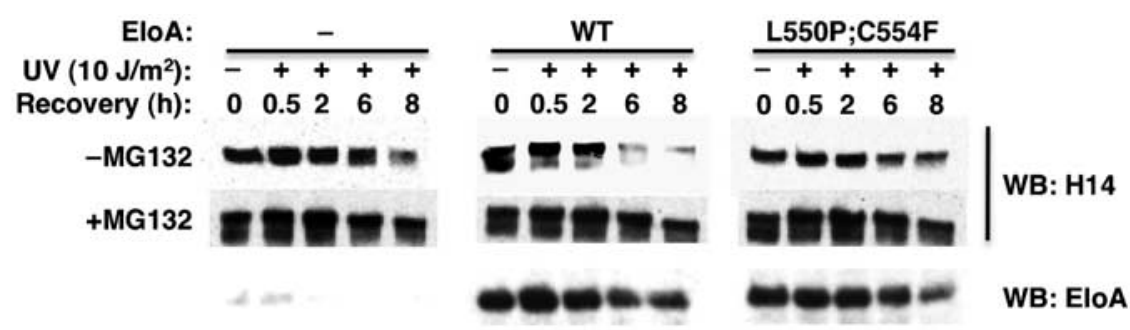

Figure 6 Wild-type Elongin A, but not Elongin A[L550P;C554F], rescues delayed degradation of Rpb1 in Elongin A-deficient cells. Elongin A ${ }^{-/-}$ ES cells transfected with either pCAG-IPG empty vector, pCAG-IPG-Flag-Elongin A, or pCAG-IPG-Flag-Elongin A[L550P;C554F] were treated with UV-irradiation $\left(10 \mathrm{~J} / \mathrm{m}^{2}\right)$ and recovered for the indicated period of time in the presence of cycloheximide with or without MG132. Total cell lysates were prepared, separated by SDS-PAGE, and immunoblotted with H14 antibody. Expression of wild-type Elongin A and Elongin A[L550P;C554F] in the absence of MG132 was detected by anti-Flag antibody.

irradiation are suppressed in Elongin A-deficient mammalian cells, but are rescued by transfection of Elongin A, (ii) that Elongin A is capable of assembling with a Cul5/Rbx2 module through Elongin $\mathrm{BC}$ and that this heteropentamer complex efficiently ubiquitylates Rpb1 in vitro, (iii) that UV-irradiation enhances not only the colocalization of Elongin A and Cul5 in cell nuclei, but also the interaction of Elongin A with the Ser5phosphorylated form of Rpb1, and (iv) that reduced expression of Elongin A and Cul5 inhibits the degradation of Ser5phosphorylated Rpb1 following UV-irradiation. Taken together, our results suggest that at least one function of mammalian Elongin A may be to act as a substrate recognition subunit of a ubiquitin ligase that is directly involved in ubiquitylation and degradation of Ser5-phosphorylated Rpb1.

\section{Mammalian Elongin A complex is one of the ubiquitin ligases that target pol II}

Using an elegant assay, Svejstrup and co-workers have recently shown that Nedd4, one of the human homologues of yeast Rsp5, acts as a ubiquitin ligase for human Rpb1, in vitro and in vivo (Anindya et al, 2007). Their conclusion that
Nedd4 is a major ubiquitin ligase of Rpb1 in mammalian cells was drawn from the findings (i) that CSA, CSB, and BRCA1, which have been thought to be the key players for Rpb1 ubiquitylation in mammals (Ljungman and Lane, 2004; Lainé and Egly, 2006; Svejstrup, 2007), turned out not to be directly involved in this process, and (ii) that UV-induced ubiquitylation of Rpb1 was significantly inhibited by RNAimediated knockdown of Nedd4. In their time course experiment, however, significantly reduced UV-dependent ubiquitylation was indeed observed in the Nedd4-knockdown cells compared with wild-type cells immediately after UV-irradiation, but after $20 \mathrm{~min}$, the levels of ubiquitylation in the two cell lines were almost comparable (Anindya et al, 2007). This result suggests the possibility that Nedd4 is not the only factor responsible for Rpb1 ubiquitylation in mammalian cells and that factors other than Nedd4 might exert their function with delayed time intervals after UV-irradiation. Our finding that maximal enhancement of the intracellular colocalization of Elongin A and Cul5 was observed 30-40 min after UV-irradiation (Figure 4A) is in good agreement with this possibility. In addition, the primary target for ubiquityla- 


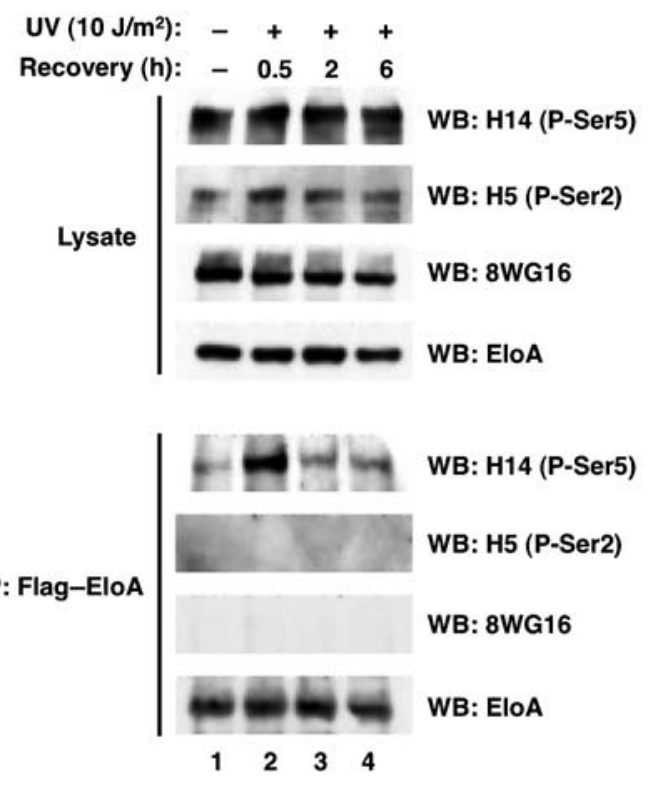

Figure 7 UV-irradiation enhances the interaction of Elongin A with the Ser5-phosphorylated form, but not with the Ser2-phosphorylated or the unphosphorylated form, of Rpb1. Elongin $\mathrm{A}^{-/-} \mathrm{ES}$ cells transfected with Flag-tagged Elongin A were treated with UVirradiation $\left(10 \mathrm{~J} / \mathrm{m}^{2}\right)$ and recovered for the indicated period of time in the presence of MG132. Total cell lysates were prepared, immunoprecipitated with anti-Flag antibody, and subjected to $6 \%$ SDS-PAGE and western blot analysis with the indicated antibodies.

tion by Rsp5 is known to be the processively transcribing Ser2-phosphorylated pol II, which predominates distal to the promoters (Komarnitsky et al, 2000; Somesh et al, 2005), whereas that of Elongin A ubiquitin ligase appears to be Ser5phosphorylated pol II, which predominates proximal to the promoters and is therefore thought to be an early elongation complex (Komarnitsky et al, 2000). Moreover, it was recently shown that the VHL protein complex, which contains Elongins B and C and a Cul2/Rbx1 module, is also induced to bind to the Ser5-phosphorylated pol II following UVirradiation and targets it for ubiquitylation in human cells (Kuznetsova et al, 2003). Thus, it is possible that Elongin A and VHL complexes might have an overlapping function in pol II ubiquitylation and that these complexes and Nedd4 may act in a complementary manner to survey transcribing pol II throughout the genome.

\section{Mechanism of activation of the Elongin A ubiquitin ligase}

What is the mechanism of activation of the Elongin A ubiquitin ligase by DNA damage? We cannot rule out the possibility that the Elongin A-Elongin BC complex and Elongin A ubiquitin ligase are constitutively present as separate complexes in cells. However, evidence suggests that many fully assembled SCF ubiquitin ligase complexes are highly unstable in cells (Zhou and Howley, 1998; Galan and Peter, 1999; Wirbelauer et al, 2000). Consistent with this, we and others have not been able to isolate a complex containing both wild-type Elongin A and Cul5 by immunoprecipitation from mammalian cell extracts (Kamura et al, 2004; Mahrour et al, 2008; and data not shown). In addition, the result of our immunofluorescence analysis shows that Elongin A and Cul5 colocalize in cells in a way that is significantly enhanced by
UV-irradiation. The transient nature of the colocalization suggests that the Elongin A ubiquitin ligase complex would be present only temporarily in cells. It is, thus, tempting to speculate that DNA damage may trigger the recruitment of the $\mathrm{Cul} 5 / \mathrm{Rbx} 2$ module to the Elongin A-Elongin $\mathrm{BC}$ complex to assemble an Elongin A ubiquitin ligase, thereby enabling transcribing pol II to be targeted for ubiquitylation, although the exact manner in which this occurs remains unknown.

\section{Role of pol II ubiquitylation by the Elongin A ubiquitin ligase}

Although ubiquitylation of pol II was originally uncovered as a response to DNA damage (Bregman et al, 1996; Ratner et al, 1998), it turned out to be rather a frequent event during transcription and also occurs in the absence of DNA damage; indeed, pol II ubiquitylation is now thought to be a general response to arrested elongation complexes (Lee et al, 2002; Somesh et al, 2005, 2007; Svejstrup, 2007). Evidence suggests that the Elongin A-Elongin BC complex has a function as a transcription elongation factor that decreases the frequency and/or duration of the transient pausing by pol II (Bradsher et al, 1993; Aso et al, 1995). We suggest that once Elongin AElongin BC encounters an arrested pol II, a Cul5/Rbx2 module may be recruited to assemble an Elongin A ubiquitin ligase, which then exerts its function to remove arrested pol II from the DNA by ubiquitylation and proteasome-mediated degradation, thereby enabling the next pol II to transcribe the gene. If the obstacle is a DNA lesion, this will also allow the DNA repair machinery access to the damage. Our results, therefore, suggest that mammalian Elongin A contributes to increasing the overall efficiency of transcript elongation in cells by at least two mechanisms-(i) by preventing transient pausing of pol II as a transcription elongation factor and (ii) by removing arrested pol II by ubiquitylation and degradation as a component of an E3 ubiquitin ligase.

\section{Materials and methods}

\section{Cell culture}

Mouse Elongin A containing an N-terminal Flag tag was amplified from pcDNA3.1-Flag-Elongin A (Tamura et al, 2003) by PCR with primers containing BamHI and NotI restriction sites and subcloned into pCAG-IPG vector (provided by $\mathrm{Dr} \mathrm{H}$ Niwa). Elongin $\mathrm{A}^{-/-} \mathrm{ES}$ cells were generated from CCE ES cells as described earlier (Yamazaki et al, 2003). Elongin $\mathrm{A}^{+/+}$and Elongin $\mathrm{A}^{-/-}+$Elongin A ES cell clones were generated by transfections of pCAG-IPG empty vector into CCE ES cells and pCAG-IPG-Flag-Elongin A into Elongin $\mathrm{A}^{-1-}$ ES cells, respectively. ES cells were cultured on gelatin-coated dishes in the absence of feeder cells in DMEM (Sigma) supplemented with $20 \%$ fetal bovine serum (FBS), glutamine, nonessential amino acids, antibiotics, $100 \mu \mathrm{M} \beta$-mercaptoethanol and recombinant LIF, as described earlier (Yamazaki et al, 2003). HeLa cells were maintained in DMEM containing $10 \%$ FBS. Cells were collected and lysed in ice-cold buffer containing $50 \mathrm{mM}$ Tris-HCl (pH 8.0), $150 \mathrm{mM} \mathrm{NaCl}, 1 \mathrm{mM}$ DTT, $0.5 \%$ (vol/vol) Triton X-100, $10 \%$ (vol/vol) glycerol, and the Complete Protease Inhibitor Cocktail (Roche Applied Science), and centrifuged at $10000 \mathrm{~g}$ for $20 \mathrm{~min}$ at $4^{\circ} \mathrm{C}$. For UV-irradiation studies, cells were washed with phosphate-buffered saline (PBS), irradiated with UV light $(254 \mathrm{~nm}$; UVP Inc.) at the indicated doses, and grown in fresh medium for various times. Cisplatin treatment $(20 \mu \mathrm{g} / \mathrm{ml})$ was for $3 \mathrm{~h}$ at $37^{\circ} \mathrm{C}$. Where indicated, $50 \mu \mathrm{M} \mathrm{H} 7,50 \mu \mathrm{M}$ DRB, $5 \mu \mathrm{M}$ MG132 or $25 \mu \mathrm{g} / \mathrm{ml}$ cycloheximide was added to cells $1 \mathrm{~h}$ before UV or cisplatin treatment. 


\section{Expression of recombinant proteins in Escherichia coli} Human Ubc5a (hUbc5a) with an N-terminal 6-histidine tag and a C-terminal FLAG tag was expressed in E. coli strain BL21(DE3) and purified by $\mathrm{Ni}^{2+}$-agarose chromatography (Kamura et al, 2000). After dialysis against $40 \mathrm{mM}$ Hepes- $\mathrm{NaOH}$ (pH 7.9), $60 \mathrm{mM}$ potassium acetate, $2 \mathrm{mM}$ DTT, $5 \mathrm{mM} \mathrm{MgCl}_{2}, 0.5 \mathrm{mM}$ EDTA, and $10 \%$ (vol $/ \mathrm{vol}$ ) glycerol, proteins were stored at $-80^{\circ} \mathrm{C}$.

\section{Expression of recombinant proteins in Sf9 insect cells}

Rat wild-type Elongin A and a series of N-terminal, C-terminal, and internal deletion mutants and a double point mutant of Elongin A, containing $3 \times$ Flag tags at their C-termini were subcloned into pBacPAK-His1. Human Cul5 containing an N-terminal HA tag was subcloned into pBacPAK-His2. Mouse Rbx2 containing an $\mathrm{N}$-terminal $3 \times$ myc tag was subcloned into pBacPAK8. Recombinant baculoviruses were generated with the BacPAK baculovirus expression system (Clontech). Baculoviruses encoding rat Elongin $\mathrm{B}$, rat Elongin $\mathrm{C}$, mouse Rbx1 containing an N-terminal myc tag, human Cul1, Cul2, and Cul3, and mouse Cul4 containing N-terminal HA tags were described earlier (Kamura et al, 1999, 2001; Aso et al, 2000). Baculovirus encoding Arapidopsis thaliana E1 with an N-terminal 6-histidine tag was provided by Dr W Krek.

Sf9 cells were cultured at $27^{\circ} \mathrm{C}$ in Grace's insect medium (Gibco) with $10 \%$ FBS and kanamycin $(100 \mu \mathrm{g} / \mathrm{ml})$ and infected with the recombinant baculoviruses indicated in the figures. Seventy-two hours after infection, cells were collected and lysed in ice-cold buffer containing $40 \mathrm{mM}$ Hepes- $\mathrm{NaOH}(\mathrm{pH} 7.9), 150 \mathrm{mM} \mathrm{NaCl}$, $1 \mathrm{mM}$ DTT, $0.5 \%$ (vol/vol) Triton X-100, $10 \%$ (vol/vol) glycerol, and the Complete Protease Inhibitor Cocktail, and centrifuged at $10000 \mathrm{~g}$ for $20 \mathrm{~min}$ at $4^{\circ} \mathrm{C}$.

\section{Immunoprecipitation and western blotting}

Anti-myc (9E10) and anti-HA (12CA5) monoclonal antibodies (Roche Applied Science), anti-Flag (M2) monoclonal antibody (Sigma), anti-RNA polymerase II monoclonal antibodies (8WG16, H14, and H5; Covance) and polyclonal antibody (N20; Santa Cruz), anti-Cul5 antibody (Santa Cruz), anti-Elongin A antibody (Yasukawa et al, 2007), anti-Elongin B antibody (Garrett et al, 1995), and antiElongin C monoclonal antibody (Transduction Laboratories) were used in immunoprecipitations and immunoblotting. Lysates of ES cells or baculovirus-infected Sf9 cells were incubated with the antibodies indicated in the figures for $1 \mathrm{~h}$ at $4^{\circ} \mathrm{C}$ and then with protein A-Sepharose (GE Healthcare) for $1 \mathrm{~h}$, or incubated with antiFLAG M2-conjugated agarose beads (Sigma) for $2 \mathrm{~h}$ at $4^{\circ} \mathrm{C}$. Beads were washed four times in buffer containing $40 \mathrm{mM}$ Hepes- $\mathrm{NaOH}$ (pH 7.9), $150 \mathrm{mM} \mathrm{NaCl}, 1 \mathrm{mM}$ DTT, $0.5 \%$ (vol/vol) Triton X-100, $10 \%$ (vol/vol) glycerol, and once in buffer containing $40 \mathrm{mM}$ Hepes- $\mathrm{NaOH}(\mathrm{pH} 7.9), 150 \mathrm{mM} \mathrm{NaCl}, 1 \mathrm{mM}$ DTT, and $10 \%$ (vol/vol) glycerol. Immunoprecipitated proteins were subjected to SDS-polyacrylamide gel electrophoresis (SDS-PAGE), transferred to a polyvinylidene difluoride membrane (Millipore), and analyzed by immunoblotting with the antibodies indicated in the figures. Immunoblots were visualized with either Western Lightning (Perkin Elmer) or SuperSignal West Femto chemiluminescent reagent (Pierce) according to the manufacturer's instructions.

\section{Assay of ubiquitylation in vitro}

RNA polymerase II was purified as described from rat liver nuclear extracts (Conaway and Conaway, 1990). To assay immunoprecipitated Elongin A complexes for their ability to activate Rpb1 ubiquitylation, Sf9 cells infected with the baculoviruses indicated in the figures were lysed as described above. After centrifugation at $10000 \mathrm{~g}$ for $20 \mathrm{~min}$ at $4^{\circ} \mathrm{C}$, the supernatants were immunoprecipitated with $2 \mu \mathrm{g}$ of anti-HA (12CA5) antibody and $10 \mu \mathrm{l}$ of protein A-Sepharose. The beads were mixed with $\sim 100 \mathrm{ng}$ of E1, $\sim 100 \mathrm{ng}$ of hUbc5a, $5 \mu \mathrm{g}$ of bovine ubiquitin (Sigma), $0.5 \mu \mathrm{g}$ of ubiquitin aldehyde (Boston Biochem), and an aliquot of purified RNA polymerase II in a $20-\mu \mathrm{l}$ reaction containing $20 \mathrm{mM}$ Tris- $\mathrm{HCl}$
(pH 7.9), $2 \mathrm{mM}$ DTT, $5 \mathrm{mM} \mathrm{MgCl}_{2}, 1.5 \mathrm{mM}$ ATP, $10 \mathrm{mM}$ creatine phosphate, $10 \mu \mathrm{g}$ of creatine phosphokinase, and $5 \mathrm{mM} \mathrm{NaF}$. Reaction mixtures were incubated for $30 \mathrm{~min}$ at $30^{\circ} \mathrm{C}$. Reaction products were subjected to $6 \%$ SDS-PAGE and analyzed by western blotting with H14 antibody.

\section{Immunofluorescence studies}

HeLa cells grown in 4-well chamber slides were UV-irradiated $\left(10 \mathrm{~J} / \mathrm{m}^{2}\right)$ and incubated for the time indicated in the figures. Cells were washed in ice-cold PBS and fixed with $2 \%$ paraformaldehyde in PBS for $20 \mathrm{~min}$ at room temperature. Cells were permeabilized in PBS containing $0.5 \%$ Triton X-100 for 20 min at room temperature and blocked in PBS containing 3\% BSA for $1 \mathrm{~h}$ at room temperature. Cells were incubated with primary antibodies at appropriate dilutions for $2 \mathrm{~h}$ at room temperature, followed by incubation with appropriate secondary antibodies at room temperature for $2 \mathrm{~h}$. To examine colocalization of Elongin A and Cul5, Elongin A was detected using anti-Elongin A mouse monoclonal antibody and Alexa Fluor 488-conjugated anti-mouse IgG antibody (Molecular Probes), whereas Cul5 was detected using anti-Cul5 rabbit polyclonal antibody (Santa Cruz) and Alexa Fluor 594-conjugated anti-rabbit IgG antibody (Molecular Probes). To examine colocalization of Elongin A and Cul2, Elongin A was detected using antiElongin A rabbit polyclonal antibody and Alexa Fluor 594conjugated anti-rabbit IgG antibody, whereas Cul2 was detected using anti-Cul2 mouse monoclonal antibody (Transduction Laboratories) and Alexa Fluor 488-conjugated anti-mouse IgG antibody. For staining DNA, cells were treated with 4,6-diamidino-2-phenylindole dihydrochloride (DAPI) from Sigma. Slides were mounted in SlowFade (Molecular Probes), and examined under an Olympus FV300 confocal laser-scanning microscope. Multiple images containing several cells were collected and representative cells are shown. All images were digitally processed for presentation using Adobe Photoshop.

\section{Isolation of MEFs}

Primary MEFs were isolated from 13.5-day-postcoitum wild-type embryos and cultured as described earlier (Miyata et al, 2007). Only nonsenescent MEFs (passages 1-3) were used for experiments.

\section{RNAi}

The mouse U6 gene promoter, followed by DNA corresponding to an shRNA sequence was subcloned into the NotI and XhoI sites of pMX-puro II, yielding pMX-puro II-U6/siRNA, as described earlier (Kamura et al, 2004). The DNA for the shRNA encoded a 21-nucleotide hairpin sequence specific to the mRNA target, with a loop sequence (-TTCAAGAGA-) separating the two complementary domains, and contained a tract of five $\mathrm{T}$ nucleotides to terminate transcription. The hairpin sequences specific for mouse Elongin A (EloA-1, EloA-2), for human Cul5 (Cul5-1, Cul5-2), and for EGFP (Clontech) mRNAs corresponded to nucleotides 1115-1135 (EloA-1), 2081-2101 (EloA-2), 1637-1657 (Cul5-1), 2202-2222 (Cul5-2), and 126-146 (EGFP) of the respective coding regions. The resulting vectors were used to transfect Plat E cells and thereby to generate recombinant retroviruses. HeLa cells stably expressing mouse ecotropic retrovirus receptor or MEFs were infected with the recombinant retroviruses. After selection, in a medium containing puromycin $(10 \mu \mathrm{g} / \mathrm{ml})$, cells were UV-irradiated $\left(10 \mathrm{~J} / \mathrm{m}^{2}\right)$ and incubated for the time indicated in the figure, and then harvested and subjected immunoblotting.

\section{Acknowledgements}

We thank $\mathrm{H}$ Niwa for pCAG-IPG plasmid and A Tsutsui for her technical assistance. This work was supported by grants from the Ministry of Education, Culture, Sports, Science, and Technology of Japan.

\section{References}

Anindya R, Aygün O, Svejstrup JQ (2007) Damage-induced ubiquitylation of human RNA polymerase II by the ubiquitin ligase Nedd4, but not Cockayne syndrome proteins or BRCA1. Mol Cell 28: 386-397
Aso T, Haque D, Barstead RJ, Conaway RC, Conaway JW (1996) The inducible elongin A elongation activation domain: structure, function and interaction with the elongin BC complex. EMBO J 15: 5557-5566 
Aso T, Lane WS, Conaway JW, Conaway RC (1995) Elongin (SIII): a multisubunit regulator of elongation by RNA polymerase II. Science 269: 1439-1443

Aso T, Yamazaki K, Amimoto K, Kuroiwa A, Higashi H, Matsuda Y, Kitajima S, Hatakeyama M (2000) Identification and characterization of Elongin A2, a new member of the Elongin family of transcription elongation factors, specifically expressed in the testis. J Biol Chem 275: 6546-6552

Bradsher JN, Jackson KW, Conaway RC, Conaway JW (1993) RNA polymerase II transcription factor SIII. I. Identification, purification, and properties. J Biol Chem 268: 25587-25593

Bregman DB, Halaban R, van Gool AJ, Henning KA, Friedberg EC, Warren SL (1996) UV-induced ubiquitination of RNA polymerase II: a novel modification deficient in Cockayne syndrome cells. Proc Natl Acad Sci USA 93: 11586-11590

Burnatowska-Hledin MA, Kossoris JB, Van Dort CJ, Shearer RL, Zhao P, Murrey DA, Abbott JL, Kan CE, Barney CC (2004) T47D breast cancer cell growth is inhibited by expression of VACM-1, a cul-5 gene. Biochem Biophys Res Commun 319: 817-825

Ceremuga TE, Yao XL, McCabe JT (2003) Cullin-5 is ubiquitous in the rat brain. Neurosci Lett 345: 121-125

Conaway JW, Conaway RC (1990) An RNA polymerase II transcription factor shares functional properties with Escherichia coli $\sigma 70$. Science 248: 1550-1553

Conaway JW, Shilatifard A, Dvir A, Conaway RC (2000) Control of elongation by RNA polymerase II. Trends Biochem Sci 25: 375-380

Duan DR, Pause A, Burgess WH, Aso T, Chen DYT, Garrett KP, Conaway RC, Conaway JW, Linehan WM, Klausner RD (1995) Inhibition of transcription elongation by the VHL tumor suppressor protein. Science 269: 1402-1406

Galan JM, Peter M (1999) Ubiquitin-dependent degradation of multiple F-box proteins by an autocatalytic mechanism. Proc Natl Acad Sci USA 96: 9124-9129

Garrett KP, Aso T, Bradsher JN, Foundling SI, Lane WS, Conaway RC, Conaway JW (1995) Positive regulation of general transcription factor SIII by a tailed ubiquitin homolog. Proc Natl Acad Sci USA 92: 7172-7176

Garrett KP, Tan S, Bradsher JN, Lane WS, Conaway JW, Conaway RC (1994) Molecular cloning of an essential subunit of RNA polymerase II elongation factor SIII. Proc Natl Acad Sci USA 91: 5237-5241

Kamura T, Burian D, Yan Q, Schmidt SL, Lane WS, Querido E, Branton PE, Shilatifard A, Conaway RC, Conaway JW (2001) MUF1, a novel Elongin BC-interacting leucine-rich repeat protein that can assemble with Cul5 and Rbx1 to reconstitute a ubiquitin ligase. J Biol Chem 276: 29748-29753

Kamura T, Koepp DM, Conrad MN, Skowyra D, Moreland RJ, Iliopoulos O, Lane WS, Kaelin WG, Elledge SJ, Conaway RC, Harper JW, Conaway JW (1999) Rbx1, a component of the VHL tumor suppressor complex and SCF ubiquitin ligase. Science 284: 657-661

Kamura T, Maenaka K, Kotoshiba S, Matsumoto M, Kohda D, Conaway RC, Conaway JW, Nakayama KI (2004) VHL-box and SOCS-box domains determine binding specificity for Cul2Rbx1 and Cul5-Rbx2 modules of ubiquitin ligases. Genes Dev 18: $3055-3065$

Kamura T, Sato S, Haque D, Liu L, Kaelin WG, Conaway RC, Conaway JW (1998) The Elongin BC complex interacts with the conserved SOCS-box motif present in members of the SOCS, ras, WD-40 repeat, and ankyrin repeat families. Genes Dev 12: 3872-3881

Kamura T, Sato S, Iwai K, Czyzyk-Krzeska MF, Conaway RC, Conaway JW (2000) Activation of HIF1 $\alpha$ ubiquitination by a reconstituted von Hippel-Lindau (VHL) tumor suppressor complex. Proc Natl Acad Sci USA 97: 10430-10435

Kipreos ET, Lander LE, Wing JP, He WW, Hedgecock EM (1996) Cul-1 is required for cell cycle exit in C. elegans and identifies a novel gene family. Cell 85: 829-839

Komarnitsky P, Cho EJ, Buratowski S (2000) Different phosphorylated forms of RNA polymerase II and associated mRNA processing factors during transcription. Genes Dev 14: 2452-2460

Kuznetsova AV, Meller J, Schnell PO, Nash JA, Ignacak ML, Sanchez Y, Conaway JW, Conaway RC, Czyzyk-Krzeska MF (2003) von Hippel-Lindau protein binds hyperphosphorylated large subunit of RNA polymerase II through a proline hydroxylation motif and targets it for ubiquitination. Proc Natl Acad Sci USA 100: 2706-2711

Lainé JP, Egly JM (2006) When transcription and repair meet: a complex system. Trends Genet 22: 430-436

Lee KB, Wang D, Lippard SJ, Sharp PA (2002) Transcription-coupled and DNA damage-dependent ubiquitination of RNA polymerase II in vitro. Proc Natl Acad Sci USA 99: 4239-4244

Ljungman M, Lane DP (2004) Transcription-guarding the genome by sensing DNA damage. Nat Rev Cancer 4: 727-737

Luo Z, Zheng J, Lu Y, Bregman DB (2001) Ultraviolet radiation alters the phosphorylation of RNA polymerase II large subunit and accelerates its proteasome-dependent degradation. Mutat Res 486: $259-274$

Mahrour N, Redwine WB, Florens L, Swanson SK, Martin-Brown S, Bradford WD, Staehling-Hampton K, Washburn MP, Conaway RC, Conaway JW (2008) Characterization of Cullin-box sequences that direct recruitment of Cul2-Rbx1 and Cul5-Rbx2 modules to Elongin BC-based ubiquitin ligases. J Biol Chem 283: 8005-8013

McKay BC, Chen F, Clarke ST, Wiggin HE, Harley LM, Ljungman M (2001) UV light-induced degradation of RNA polymerase II is dependent on the Cockayne's syndrome A and B proteins but not p53 or MLH1. Mutat Res 485: 93-105

Miyata K, Yasukawa T, Fukuda M, Takeuchi T, Yamazaki K, Sakumi K, Tamamori-Adachi M, Ohnishi Y, Ohtsuki Y, Nakabeppu Y, Kitajima S, Onishi S, Aso T (2007) Induction of apoptosis and cellular senescence in mice lacking transcription elongation factor, Elongin A. Cell Death Differ 14: 716-726

Ohta T, Michel JJ, Schottelius AJ, Xiong Y (1999) ROC1, a homolog of APC11, represents a family of cullin partners with an associated ubiquitin ligase activity. Mol Cell 3: 535-541

Price DH, Sluder AE, Greenleaf AL (1989) Dynamic interaction between a Drosophila transcription factor and RNA polymerase II. Mol Cell Biol 9: 1465-1475

Querido E, Blanchette P, Yan Q, Kamura T, Morrison M, Boivin D, Kaelin WG, Conaway RC, Conaway JW, Branton PE (2001) Degradation of p53 by adenovirus E4orf6 and E1B55K proteins occurs via a novel mechanism involving a Cullin-containing complex. Genes Dev 15: 3104-3117

Ratner JN, Balasubramanian B, Corden J, Warren SL, Bregman DB (1998) Ultraviolet radiation-induced ubiquitination and proteasomal degradation of the large subunit of RNA polymerase II. Implications for transcription-coupled DNA repair. J Biol Chem 273: $5184-5189$

Ribar B, Prakash L, Prakash S (2007) ELA1 and CUL3 are required along with ELC1 for RNA polymerase II polyubiquitylation and degradation in DNA-damaged yeast cells. Mol Cell Biol 27: 3211-3216

Roeder RG (1996) The role of general initiation factors in transcription by RNA polymerase II. Trends Biochem Sci 21: 327-335

Selby CP, Sancar A (1997) Cockayne syndrome group B protein enhances elongation by RNA polymerase II. Proc Natl Acad Sci USA 94: 11205-11209

Shilatifard A, Conaway RC, Conaway JW (2003) The RNA polymerase II elongation complex. Annu Rev Biochem 72: 693-715

Shilatifard A, Lane WS, Jackson KW, Conaway RC, Conaway JW (1996) An RNA polymerase II elongation factor encoded by the human ELL gene. Science 271: 1873-1876

Sims III RJ, Belotserkovskaya R, Reinberg D (2004) Elongation by RNA polymerase II: the short and long of it. Genes Dev 18 : 2437-2468

Somesh BP, Reid J, Liu WF, Søgaard TM, Erdjument-Bromage H, Tempst P, Svejstrup JQ (2005) Multiple mechanisms confining RNA polymerase II ubiquitylation to polymerases undergoing transcriptional arrest. Cell 121: 913-923

Somesh BP, Sigurdsson S, Saeki H, Erdjument-Bromage H, Tempst P, Svejstrup JQ (2007) Communication between distant sites in RNA polymerase II through ubiquitylation factors and the polymerase CTD. Cell 129: 57-68

Svejstrup JQ (2007) Contending with transcriptional arrest during RNAPII transcript elongation. Trends Biochem Sci 32: 165-171

Tamura K, Miyata K, Sugahara K, Onishi S, Shuin T, Aso T (2003) Identification of EloA-BP1, a novel Elongin A binding protein with an exonuclease homology domain. Biochem Biophys Res Commun 309: $189-195$

Wind M, Reines D (2000) Transcription elongation factor SII BioEssays 22: 327-336 
Wirbelauer C, Sutterlüty $\mathrm{H}$, Blondel $\mathrm{M}$, Gstaiger $\mathrm{M}$, Peter M, Reymond F, Krek W (2000) The F-box protein Skp2 is a ubiquitylation target of a Cull-based core ubiquitin ligase complex: evidence for a role of Cul1 in the suppression of Skp2 expression in quiescent fibroblasts. $E M B O J$ 19: 5362-5375

Yamazaki K, Aso T, Ohnishi Y, Ohno M, Tamura K, Shuin T, Kitajima S, Nakabeppu Y (2003) Mammalian Elongin A is not essential for cell viability but is required for proper cell cycle progression with limited alteration of gene expression. J Biol Chem 278: $13585-13589$
Yamazaki K, Guo L, Sugahara K, Zhang C, Enzan H, Nakabeppu Y, Kitajima S, Aso T (2002) Identification and biochemical characterization of a novel transcription elongation factor, Elongin A3. J Biol Chem 277: 26444-26451

Yasukawa T, Sugimura K, Fukuda M, Yamazaki K, Kitajima S, Okumura K, Aso T (2007) Functional characterization of a mammalian transcription factor, Elongin A. Biochem Biophys Res Commun 352: 237-243

Zhou P, Howley PM (1998) Ubiquitination and degradation of the substrate recognition subunits of SCF ubiquitin-protein ligases. Mol Cell 2: 571-580 